is used primarily for the nitrogen it contains, but it is there and should be differentiated from the other more available forms. Regarding this point there seems to be a wide divergence of opinions among certain authorities. Stutzer ("Die Behandlung und Anwendung des Standdüngers") says that the nitrogen of peat has no value because of the long interval of time required to render it available. Storer, in his book on agriculture, recognizes its comparative inertness but states "that it is a matter of familiar observation and experience that the peat nitrogen may be made to contribute to the support of crops and that it has consequently a considerable money value." He also quotes Nessler as follows: "Although the nitrogenous constituents of peat decompose in the soil more slowly than the altered ossein in meal from steamed bones they do nevertheless in some cases decompose more quickly than the nitrogenous components of wool, or than the ossein in coarse meal from raw bones or than those in leather meal, either that or from torrified leather."

As to the quantity of nitrogen to be found in peat, Dr. Johnson reports that he found upon the examination of thirty samples from Connecticut an average of 1.5 per cent. with a maximum of 2.9 per cent. In the course of a study of New Jersey peats, I 23 samples have been examined in my laboratory. The nitrogen has ranged from 0.74 per cent. to 2.83 per cent. with an average of 1.75 per cent.

RUTGERS COLLEGE,

NEW BRUNSWICK, N. J

\title{
NEW BOOKS.
}

Electrical Naturh of Matthe and Radioactivity. By Harry C. Jones, Professor of Physical Chemistry in Johns Hopkins University. New York: D. Van Nostrand Co. 1906 viii +212 pp. Price, $\$ 2.00$.

The author states that the contents of this book had been published previously, as a series of articles, in the Electrical Review; the present work is a revised edition of these articles. "The aim of the writer has been to present the more important facts and conclusions in connection with the work on the electrical nature of matter and radioactivity as far as possible in nonmathematical language. $* * *$ While the work is written in semi-popular style, the attempt has been made to treat the subject with scientific accuracy." A perusal of the book shows that Professor Jones has accomplished very satisfactorily the objects announced in the preceding lines quoted from the preface.

The first four chapters deal with the electrical conductivity 
of gases, the nature of the electrons constituting the cathode rays, and the evidence of the electrical nature of matter. In the fifth chapter, X-rays and Becquerel or $\beta$-rays, and the identity of the latter with cathode rays are discussed. The next six chapters treat of the discovery of radium and of the phenomena of radioactivity. These are followed by three chapters on radioactive emanations and induced radioactivity. The concluding four chapters deal chiefly with the spontaneous transformation of matter and the explanation of the phenomena of radioactivity by means of the disintegration hypothesis and the electron hypothesis regarding the nature of the atom.

There are numerous references to the original literature, but no attempt has been made at completeness in this direction. There is a good index. A few misleading or erroneous statements exist. On p. I4I it is stated that after the separation of UX, the remaining uranium was not appreciably radioactive. This is of course true if the activity is measured photographically, but electrical measurements show that the ionizing power of uranium is but slightly altered by the removal of UX. On p. 147 it is stated that thorium precipitated three times by ammonia is only about one one-hundredth as radioactive as ordinary thorium; the correct statement is found on p. I93. The book is well up-to-date and includes discussions of much of the most important work of the year 1905. It will give the general reader an adequate idea of the nature of the most important achievements in this field of science. It will also serve as a good introduction to the advanced treatises of J. J. Thomson and of Rutherford and to the original literature, for those who wish to study the subject thoroughly.

H. N. McCoy.

LECTURE-Notes on Chemistry for DHNTAI, Students. By H. Cartton Smith, Pr.G. New York: John Wiley \& Sons. 1906. viii+273 pp. Price, $\$ \mathbf{2 . 5 0}$.

This course in dental chemistry includes the following subjects: Qualitative Analysis, Dental Metallurgy, Volumetric Analysis, Microchemical Analysis, Organic Chemistry, Physiological Chemistry, Digestion, Urine. If the students of the Harvard Dental School, for whom the course was prepared, have found it sufficient for their needs, they must be made of better stuff than ordinary students. For if the latter were reasonably familiar with elementary general chemistry, it seems clear that only the 